\title{
A IDEOLOGIA NA EDUCAÇÃO E DIDÁTICA BRASILEIRA: UMA PEDRA NO CAMINHO PARA UMA PRÁXIS LIBERTADORA
}

Carolina Machado Saraiva de Albuquerque Maranhão ${ }^{1}$

Pedro Nunes Gouveia²

Flávia Carolini Pereira Santo 3

\section{Resumo}

A linguagem do conhecimento foi alterada para aquela que mais se aproximou dos interesses do capital privado, prejudicando o fomento da crítica e do pensamento heterodoxo nas metodologias pedagógicas, substituindo-as pelo simples racionalismo positivista - entusiasta aos burgueses - ao sacralizar a industrialização e o progresso capitalista pela técnica e pela ciência. Não somente a educação, mas gradativamente, grande parte do processo formativo (ADORNO, 1966) no Brasil, têm sido vítimas de ameaças de diversas políticas e planos que promovem a massificação cultural, entendendo-a como obra da indústria cultural (ADORNO e HORKHEIMER, 1995) e extinguem as possibilidades de uma percepção mais crítica da sociedade. A partir dessa premissa, o presente artigo esforça-se em analisar e dissertar sobre os interesses e impactos de tais políticas, colocando sobre análise os malefícios das mesmas na formação da consciência humana e transmissão do conhecimento.

Palavras-chave: Semiformação. Educação. Ideologia.

\section{THE IDEOLOGY IN BRAZILIAN EDUCATION AND DIDACTICS: A STUMBLING ROCK TOWARDS LIBERATING PRAXIS}

\footnotetext{
Abstract

1 Professora Adjunta da Universidade Federal de Ouro Preto. Coordenadora do Observatório C.A.F.E. Observatório em Crítica, Formação e Ensino em Administração. E-mail: prof@carolmaranhao.com.br

2 Graduando em Administração da Universidade Federal de Ouro Preto. Integrante do Observatório C.A.F.E. - Observatório em Crítica, Formação e Ensino em Administração. E-mail: nunesgou@hotmail.com.br.

3 Graduada em Administração da Universidade Federal de Ouro Preto. Integrante do Observatório C.A.F.E. - Observatório em Crítica, Formação e Ensino em Administração. E-mail: flaviapereirasantos2011@hotmail.com
} 
The language of knowledge was changed to the one that most approached the interests of private capital, harming the promotion of criticism and heterodox thinking in pedagogical methodologies, replacing them with simple positivist rationalism - enthusiastic to the bourgeoisie - by sacralizing industrialization and progress capitalist by technique and science. Not only education, but gradually, much of the formative process in Brazil, has been victims of threats from various policies and plans that enhance cultural massification and extinguish the possibilities of a more critical perception of society. Based on this premise, the present article analyzes and discusses the interests and impacts of such policies, analyzing the negative effects of these policies on the formation of human consciousness and the transmission of knowledge.

Keywords: Semiformation. Education. Ideology.

\section{LA IDEOLOGÍA EN LA EDUCACIÓN Y LA ENSEÑANZA BRASILEÑA: UNA PIEDRA EN EL CAMINO HACIA UNA PRAXIS LIBERADORA}

\section{Resumen}

El conocimiento del idioma se cambió a uno que estuvo más cerca de los intereses privados de capital, lo que socava el desarrollo del pensamiento crítico y poco ortodoxo en los métodos de enseñanza, sustituyéndolos por la sencilla racionalismo positivista - aficionado a los burgueses - para consagrar la industrialización y el progreso capitalista por la técnica y la ciencia. No sólo la educación, pero poco a poco, la mayor parte del proceso de formación en Brasil, han sido víctimas de amenazas de diversas políticas y planes que promuevan la masificación cultural y extingue la posibilidad de una percepción más crítica de la sociedad. A partir de esta premisa, este artículo pretende analizar y trabajar sobre los intereses y los impactos de tales políticas, poniendo en el análisis de los efectos nocivos de la misma en la formación de la conciencia humana y la transmisión del conocimiento.

Palabras-clave: La Erudición. La Educación. La Ideología.

\section{Introdução}

Empenhar-se na tentativa de analisar para compreender a complexa realidade do sistema educacional brasileiro requer de todo e qualquer 
interessado no assunto um verdadeiro aprofundamento nas bases históricas e sociológicas presentes no processo dinâmico do pensamento crítico no Brasil. Influenciados pelo pragmatismo do ideário neoliberal, o Estado brasileiro, comumente nas últimas décadas, adotou políticas educacionais que expandiram gradualmente a privatização do ensino, principalmente o superior.

Nosso objetivo com este trabalho é discutir sobre as ideologias numulárias, colocando sobre análise os impactos massificadores dessas políticas sobre a formação da consciência humana e na transmissão do conhecimento. Pretende-se reiterar o papel da semiformação, principalmente no processo de objetivação quantitativa e privatização do sistema educacional público brasileiro. A impertinente existência de algumas graves lacunas na Educação Brasileira coloca em jogo o caráter dos programas e planos investidos nessa área, empregados nos últimos anos. "Os sistemas de colapso da formação cultural que se fazem observar em toda parte, mesmo no estrato das pessoas cultas, não se esgotam com as insuficiências do sistema e dos métodos da educação, sob a crítica de sucessivas gerações." (ADORNO, 1996, p. 01).

No texto “A Teoria da Semicultura" (1996), Adorno já apresenta a ineficiência das constantes reformas educacionais no tocante à formação crítica. A chamada "crise da escola", tão largamente apontada por estudiosos de diversas correntes de pensamento somente fazem afirmar a ontologia do estado falso da educação como práxis para a aptidão à experiência. Na semiformação, a educação é capaz somente de formar consciências danificadas, obliteradas em suas capacidades reflexivas, petrificadas pela autoconservação. Os sujeitos semiformados são obstruídos em suas capacidades de se "tornarem experientes", ou seja, de realizarem experiências formativas com o mundo, cerne de uma educação crítica. A semiformação é a realização máxima da formação cultural no capitalismo, em que os sujeitos são conformados à esfera adaptativa da vida social.

Sob a égide da Indústria Cultural (ADORNO e HORKHEIMER, 1995), a educação se torna mais uma mercadoria. Esvaziada, com seus sentidos petrificados, a educação perde sua transcendência quando está sob o julgo da Indústria Cultural. Esta presta dois grandes "serviços aos seus consumidores", dizem Adorno e Horkheimer (1995): (1) ela classifica os sujeitos, categoriza-os e pré-define-os em termos de suas formações culturais; (2) ela entrega aos sujeitos a interpretação dos bens culturais, seus sentidos e suas funções. Ela elimina, assim, a capacidade do sujeito de ser sujeito. A ele, não resta mais nada a ser descoberto, sob o domínio do Esclarecimento, a razão se tornou mito e o sujeito se submete ao domínio da natureza (ADORNO e HORKHEIMER, 1995). 
A ausência da teoria crítica no ambiente da sala de aula e no contexto das instituições escolares é, para Giroux (1990), o fator que impede a constituição de uma intelectualidade crítica, propulsora de uma perspectiva emancipatória que auxilie na redução do panorama de inúmeras desigualdades e injustiças sociais. Uma vez imersa na sociedade neoliberal da livre informação e tecnologização do conhecimento, as figuras que estabelecem a maiêutica socrática desaparecem e a "arte de dar a luz" na reconstrução das concepções humanas é pervertida em parâmetros empobrecedores da qualidade do ensino.

O papel do Estado é reduzido drasticamente ou se torna influenciável na edição de programas educacionais em que "importa menos a democratização e o acesso ao conhecimento e à apropriação dos instrumentos necessários para um desenvolvimento intelectual e humano da totalidade das crianças e dos jovens e mais efetivar a expansão quantitativa da escola" (PIMENTA et al., 2005, p. 41).

\footnotetext{
Os saberes teóricos propositivos se articulam, pois, aos saberes da prática, ao mesmo tempo ressignificando-os e sendo por eles ressignificados. O papel da teoria é oferecer aos professores perspectivas de análise para compreenderem os contextos históricos, sociais, culturais, organizacionais e de si mesmos como profissionais, nos quais se dá sua atividade docente, para neles intervir, transformando-os (PIMENTA et al., 2005, p. 26).
}

Ademais é necessário considerar as implicações que explicam, ainda de que forma não completa, a peculiaridade das características culturais e a pedagogia adotada nos últimos tempos pela sociedade capitalista ocidental e também oriental, pois, como explicita Goya (2008), ambos os polos apresentam uma latente necessidade de consumir característica comum aos indivíduos do século XX - sendo esse processo fruto da industrialização, que independe de qualquer estrutura política. Traduz-se na atualidade, portanto, uma literal aplicação ideológica, cuja principal fonte é o poder do capital que fomenta além do campo econômico, as práticas sociais, políticas e psicoafetivas, além de todo conhecimento humano.

No Brasil, independentemente da orientação política adotada pelos partidos que assumiram o governo nos últimos anos - esquerda, centro ou direita - foram formuladas deliberadamente políticas e programas cujas bases promulgam a primazia dos interesses econômicos. Difícil é pensar e não contestar alguns fatores da ideologia presente no funcionamento das iniciativas governamentais no campo educacional, que mesmo após a grande expansão e crescimento do setor educacional, evidenciados nas inúmeras iniciativas que elevaram o número de cidadãos inscritos nesse sistema, os mesmos espaços cresceram também qualitativamente por meio 
de uma pedagogia que não estabeleça uma convergência de interesses pecuniários e restritos a manutenção desse ciclo, todos esses expressivamente maléficos à pura formação dos indivíduos.

\section{A Ideologia absoluta: lobo do próprio homem}

No aprofundamento do conceito de ideologia, bem como em suas implicações, é inegável o ato de que a mesma cria valores culturais assimilados sem grande dificuldade pela sociedade. Shilds (1968) reitera que por serem fechadas, explícitas e inflexíveis a qualquer tipo de inovação, implantam-se de maneira dócil e cativante, a fim de garantir o empenho total de seus adeptos. Inerte a um panorama de domínio do anacronismo da semiformação, a educação - baluarte das expressões culturais - é transpassada por interesses que retiram a essência filosófica na teoria do conhecimento, reduzindo-a a uma simples visão dogmática que, segundo Hessen (2003), retrata a concepção epistemológica primitiva, sendo, portanto, um parecer ingênuo e incompleto do mundo, por retratar um pensar ausente de espanto e provocação para admirar e problematizar o mundo e os homens, instrumentalizando a razão para o alcance de determinado fim, calculando utilidades e resultados.

\footnotetext{
O contato entre sujeito e objeto não pode parecer questionável se não se vê que o conhecimento apresenta-se numa relação. É o que ocorre com o dogmático. Ele não vê que o conhecimento é, essencialmente, uma relação entre sujeito e objeto. Ao contrário, acredita que os objetos de conhecimento nos são dados como tais, e não pela função mediadora do conhecimento (e não apenas por ela). [...] Os objetos nos seriam dados diretamente, corporeamente, e assim também os objetos do pensamento. Num caso desconsidera-se a percepção, por meio da qual determinados objetos nos são dados; no outro desconsidera-se a função pensante (HESSEN, 2003, p. 29-30).
}

Como se estabelecerá um discurso plausível e minimamente racional, se o conhecimento é respaldado por ideologias que dogmatizam conceitos, podando ou colonizando qualquer tipo de pensamento fora do escopo defendido por ela? O questionamento anterior traz à tona o que se trata de um verdadeiro cercear das liberdades da reflexão e ação autônoma do homem, ainda que por meios muitas vezes imperceptíveis e atraentes - o que tornam as armadilhas ideológicas mais perniciosas e graves à emancipação do conhecimento intuitivo e da possibilidade de uma vivência cotidiana não autonomizada. O próprio advento, no Iluminismo, da ideologia como uma ciência que oferece um parecer racional das leis e princípios que desenvolvem as ideias era fruto de um 
conjunto de interesses, ou seja, inevitavelmente partia de outra ideologia. Como é ilustrado a seguir:

\begin{abstract}
Por outro lado, o apelo a uma natureza desinteressada, à ciência e à razão, em oposição à religião, à tradição e à autoridade política, simplesmente mascarava os interesses do poder a que estas nobres noções secretamente serviam. Poderíamos então arriscar o paradoxo de que a ideologia nasceu como uma crítica totalmente ideológica da ideologia. Ao iluminar o obscurantismo da velha ordem, lançou sobre a sociedade uma luz ofuscante, que cegou homens e mulheres para as fontes sombrias dessa claridade. [...] Se toda consciência é materialmente condicionada, isso não deveria aplicar-se também às noções aparentemente livres e desinteressadas que iluminariam as massas em seu caminho para fora da autocracia, rumo à liberdade? Se tudo deve ser submetido à luz translúcida da razão, não se deveria incluir aí a própria razão? (EAGLETON, 1997, p. 66).
\end{abstract}

Williams (1992) reafirma a importância da cultura como reflexo de interesses - a criação de um espírito formador e a tradução de uma realidade vivenciada. Ou seja, por meio de um sistema de significações, a cultura toma o papel de transmissora da ordem social estabelecida, influenciando "de modo a incluir não apenas as artes e as formas de produção intelectual tradicionais, mas também todas as 'práticas significativas' - desde a linguagem, passando pelas artes e filosofia, até o jornalismo, moda e publicidade" (WILLIAMS, 1992, p. 13).

Em contrapartida, Williams (1977, p. 132) induz a possibilidade de que "nenhuma ordem social dominante, e, portanto, nenhuma cultura dominante, jamais inclui ou esgota, na realidade, toda prática humana, energia humana e intenção humana". Eagleton (1997) afirma que, para Williams, nenhuma ideologia ou cultura pode ser hegemônica, pois a própria formação social é fruto da junção de consciências dominantes, residuais e emergentes. Apesar de entender que a ideologia não coíbe totalmente o modo de pensar do homem, tornando-o um ser totalmente inerte e impossibilitando alguma opção de vivificação intelectual, é inegável salientar que a mesma dilacera a reflexão crítica e acaba por tornar deficiente a formação de uma consciência cidadã plena. $\mathrm{O}$ fato é que a ideologia, a fim de garantir seu sustento, aposta na padronização dos parâmetros do pensamento social. Mesmo que sua teoria se aproxime de ideais beneméritos, a tentativa de confluir seus esforços na congeneridade das visões sobre o mundo, eliminando a crítica e a especulação filosófica, torna-a um instrumento perverso de alienação ao não aceitar valores fundamentais na emancipação dos sujeitos. 
$\mathrm{Na}$ arena política da sociedade burguesa, todos os homens e mulheres são abstratamente iguais como votantes e cidadãos, mas essa equivalência teórica serve para mascarar suas desigualdades concretas no âmbito da "sociedade civil". [...] Para o marxista da Escola de Frankfurt Theodor Adorno, esse mecanismo abstrato é o próprio segredo da ideologia. A troca de mercadorias efetua uma equação entre as coisas que são, na verdade, incomensuráveis, e, para Adorno, o mesmo ocorre com o pensamento ideológico. [...] a ideologia é uma forma de "pensamento de identidade" - um estilo veladamente paranoico de racionalidade, que transmuta inexoravelmente a singularidade e a pluralidade das coisas em mero simulacro de si ou que as expulsa para além de suas fronteiras, em um ato de exclusão dominado pelo pânico. Por isso, o oposto da ideologia não seria a verdade ou a teoria, mas a diferença ou a heterogeneidade (EAGLETON, 1997, p. 115-116).

Historicamente, a sociedade brasileira é permeada desde seu início por valores positivistas que apregoam essencialmente a "ordem" e o "progresso" - que inclusive são lemas da bandeira nacional - e dessa maneira cultivam, ainda que implicitamente, determinadas visões ideológicas utilitaristas que sustentam a divisão de classes sociais e econômicas, calcadas na mecanização do trabalho e por uma massificação técnica do intelectual. Inserida nesse panorama de uma reorganização social instauradora da ordem positivista, a Educação se tornou uma das maiores forças de manobra de políticas econômicas que legitimem a exploração da formação do homem pelo trabalho e a divisão discrepante das classes socioeconômicas, uma vez que garante nesse processo as instruções necessárias para o desenvolvimento progressivo do setor privado, distanciando e tornando utópica a concretização dos valores humanistas e de um ideário social plausível a realidade nacional e a livre das sombras escrupulosas da desigualdade e censura a liberdade do espírito e da consciência emancipada.

\footnotetext{
Quanto aos estudos positivos, sabiamente concebidos e convenientemente dirigidos, não comportam de modo algum tal influência. Aliando-se e aplicando-se por sua natureza a todos os trabalhos práticos, tendem, ao contrário, a confirmar ou mesmo inspirar o gosto por eles, quer enobrecendo seu caráter habitual, quer adoçando suas consequências penosas. Conduzindo, de resto, a uma sadia apreciação das diversas posições sociais e das necessidades correspondentes, predispõem a perceber que a felicidade real é compatível com todas e quaisquer condições, desde que sejam desempenhadas com honra e aceitas convenientemente (COMTE, 1978, p. 207).
}

Para Adorno (1996) a formação cultural torna-se uma antinomia na qual seu sentido se torna algo alheio ao mundo e sua realidade, sendo a semiformação, ao contrário de sua antítese, uma maneira de integração, pois obstrui “como pedantismo inócuo ou presunçosa insubordinação, o 
caminho do amanhã." (ADORNO, 1996, p. 8). A pura formação se constitui como esse caminho, pois, segundo Camozzatto (2012), tem por objetivo almejar uma transformação do caráter ideológico e empírico dos sujeitos, sendo que sua aplicação acaba por extrapolar os espaços institucionais, abrangendo as relações e forças produtivas de toda a comunidade.

Entretanto, o vasto referencial estatístico abordado no estudo de Schwartzman (2005) revela que a realidade educacional brasileira não condiz com o sentido verdadeiro do conhecimento, uma vez que é incipiente a grande parte das atuais metodologias pedagógicas aplicadas no Brasil. Além disso, são aplicados sucessivos planos, programas e novos sistemas técnico-burocráticos capazes de designar para que público o sistema educacional se dirigirá, reafirmando a desigualdade socioeconômica nacional e, o que é mais execrável, com qual ideologia ou interesse estará aliado à sua transmissão. Historicamente no Brasil, as políticas de regulamentação do ensino universitário oscilaram quanto à intensidade de sua fiscalização e a consistência real de suas propostas. Entretanto, independente da época e de qual governo as encabeçaram, tais iniciativas fracassaram em forçar que o mercado garanta o aumento da qualidade na transmissão do conhecimento (CASTRO, 2005).

\footnotetext{
Reformas pedagógicas isoladas, indispensáveis, não trazem contribuições substanciais. Poderiam até, em certas ocasiões, reforçar a crise, porque abrandam as necessárias exigências a serem feitas aos que devem ser educados e porque revelam uma inocente despreocupação frente ao poder que a realidade extrapedagógica exerce sobre eles (ADORNO, 1996, p. 1).
}

Reduzida em um processo mecânico de ensino voltado ao alcance de objetivos e metas capitalistas, a aprendizagem e a formação, para Ghedin (2005), são resumidos ao estudo da prática e não da práxis, sendo que a última exige em sua operacionalização a ação associada à reflexão. Por meio de uma epistemologia da práxis, a ação não seria meramente executada como uma técnica alienatária, mas reconheceria em si própria a identidade humana, seu espaço social e sua visão verossímil dos fatos e acontecimentos.

Como explicita Cruz (2015), desde a Reforma Universitária de 1968, no auge da repressão militar, e durante os governos de Fernando Henrique Cardoso (1995 - 2002) e Luis Inácio Lula da Silva (2003 - 2010), até seus desdobramentos nos dias atuais, emprega-se um movimento de desestatização da Educação, cuja consequência se encontra em suas precariedade e sucateamento. Ao ser implantado, dentre as metodologias de ensino, sistemas de produtividade aliada a práticas gerenciais de eficácia e eficiência, Freitag (1996) passa a considerar e denominar os 
espaços que sofrem esses dilaceramentos como "universidades operacionais".

De fato, a cultura brasileira salientou grande protagonismo em fortes momentos de censura política e cerceamento da liberdade de expressão. Entretanto, notórias são as diferenças entre os pensamentos críticos de grande parte dos cidadãos de meio século atrás - inseridos em pleno contexto de repressão militar - com os que vivem hoje em um sistema democrático. A apatia ou o ínfimo interesse no aprofundamento dos problemas sociais brasileiros são estarrecedores e nos levam a refletir sobre o protagonismo das atuais influências culturais nos jovens brasileiros. Para Pucci (2009), a tentativa política de garantir um suposto acesso igualitário à educação, por meio de excessivos e sofisticados aparelhamentos tecnológicos, aceleraram o processo de espetacularização do conhecimento, relativizando a formação de uma consciência sólida dos sujeitos sobre sua realidade.

Alheios aos instrumentos sedutores da Indústria Cultural e a objetivação do homem - comum ao ideário numulário - expressivas massas da sociedade brasileira acabam por coibir, ainda que involuntariamente, a possibilidade de portarem uma visão crítica sobre as incoerências sistemáticas, capaz de enxergar os latentes prejuízos dessas artimanhas no processo de desenvolvimento de uma individualidade genuína. Cria-se um panorama favorável para a alienação dos cidadãos, pois influenciados às modas atraentes ditadas pelo ambiente em que vivem, cultivam em si um desinteresse pela autorreflexão e especulação filosófica, elementos que para Adorno (1996) são fundamentais para o reconhecimento do homem em sua essência e a para afirmação do papel de autor de sua própria existência.

No entanto, o a-priori do conceito de formação propriamente burguês, a autonomia, não teve tempo algum de constituir-se e a consciência passou diretamente de uma heteronomia a outra. No lugar da autoridade da Bíblia, se instaura a domínio dos esportes, da televisão e das "histórias reais", que se apoiam na pretensão de literalidade e de facticidade aquém da imaginação produtiva (ADORNO, 1996, p. 6).

Existe um discurso aparente de contradição a esse processo, pois é repleto por um vazio ideológico que se coopta a própria realidade. $\mathrm{O}$ sonho de uma formação pura é performático e falsificado em apologia de um mundo organizado, admitindo a si uma catarse simbólica ao confinálo ao ciclo ideológico, sem pensar numa maneira de torná-lo adaptável ao presente. "A formação cultural controlável, que se transformou a si mesma em norma e em qualificações equivale à cultura geral que se degenera no palavrório dos vendedores" (ADORNO, 1996, p. 13). 
Para Adorno (1996), o momento de espontaneidade que distingue a formação dos mecanismos de domínio social da natureza, desintegra-se em avaliações que em muito pouco exprimem a Paidéia, o processo do homem em desenvolver o conhecimento de si e do mundo. "A formação esquiva-se do autodidatismo, é de árdua conquista pelos próprios punhos e, se adquirida, tende à má posse" (ADORNO, 1996, p. 13). Fromm (1970) não ressalva apenas a massificação da autoestima e da autoavaliação humana, mas do reconhecimento da identidade presente na própria pessoa com sua independência refletida em uma práxis libertadora. Retratando e adaptando essas ideias ao ambiente escolar, fica cada vez mais claro perceber que o fomento da crítica nesses espaços é essencial para a organicidade de uma prática reflexiva que reconheça a partir de um pensamento crítico sobre a realidade não somente o que convém particularmente ao indivíduo, mas aquilo que traga benefícios equivalentes a todos. Seria, portanto, um retorno a valores humanísticos que já tínhamos cultivado anteriormente em nossa cultura, mas que progressivamente substituímos por uma espécie de indulto a mecanicismos que nos trazem enriquecimento.

\footnotetext{
Como o homem moderno se sente ao mesmo tempo como o vendedor e a mercadoria a ser vendida no mercado, sua autoestima depende de condições que escapam a seu controle. Se ele tiver sucesso, será "valioso"; se não, imprestável. O grau de insegurança daí resultante dificilmente poderá ser exagerado. [...] Por isso, a pessoa é compelida a lutar incessantemente pelo sucesso, e qualquer retrocesso é uma grave ameaça à sua autoestima: o resultado disso são sentimentos de incapacidade, insegurança e inferioridade. Se as vicissitudes do mercado são os juízes de valor da gente desaparece o sentimento de dignidade e brio (FROMM, 1970, p.73).
}

Esses valores não se situam como uma maneira de imposição e muito menos a crítica pode se converter em si mesma. Pelo contrário, é na coletividade e somente por ela que a crítica se torna plausível ao fomentar o debate e a discussão de conhecimentos, fazendo com que as ideias ultrapassem o nível do discurso e encontrem meios para sua concretização real na sociedade (CONTRERAS, 1997). "Símbolo de uma consciência que renunciou à autodeterminação, prende-se de maneira obstinada, a elementos culturais aprovados. Sob seu malefício gravitam como algo decomposto que se orienta à barbárie" (ADORNO, 1996, p. 1).

A semiformação, para Adorno (1996), não se reduz à pedagogia e nem à sociologia, mas é fruto da relação dialética entre essas duas vertentes. Ou seja, a ausência da crítica ou a presença de uma cultura alienada não se restringe ao ensino-aprendizagem na sala de aula e nem ao macro sistema social. É, de fato, o aprisionamento da formação nas 
malhas da socialização, um grave quadro de alienação, que extrapola o contexto de casos isolados e nascem da totalidade social. Uma renúncia à autodeterminação e fuga a toda angustia presente na emancipação e a consequente responsabilidade advinda da liberdade - transforma o reconhecimento do problema em um tabu e a identificação crítica da práxis em algo tão abstrato que "apenas assinala um ponto cego ao qual deveria se aplicar o trabalho do conhecimento" (ADORNO, 1996, p. 2).

Portanto, trata-se de uma consciência maniqueísta que aos poucos se separa, torna-se absoluta e isola-se das coisas humanas, assimilando elementos culturais aprovados que rechaçam a totalidade e que se constituem em bens. Adorno (1996) exorta a análise de Max Frisch ao considerar que a conversão da cultura em um valor afirma sua impotência - a cultura emerge na incoerência da ação alienada - ao mesmo tempo em que homens notáveis dedicavam-se energeticamente e intelectualmente aos bens culturais, os mesmos "puderam se encarregar tranquilamente da práxis assassina do nacional-socialismo” (ADORNO, 1996, p. 2).

A tentativa de persuasão e opressão social originadas do desenvolvimento tecnológico-industrial rouba toda e qualquer oportunidade de criatividade emancipatória ao ocupar deliberadamente os espaços institucionais de Educação, através do livre financiamento de grande parte das cátedras, reduzindo o espaço crítico a exceções de pesquisadores cada vez mais escassos, que ao persistirem por uma relação dialética que desconstrua a mimetização semiformativa, sofrem grande rejeição não somente de setores da comunidade acadêmica, mas também o preconceito das parcelas sociais massificadas. "O semiformado culturalmente se coloca todas as vezes entre os salvos, e, entre esses, inclui quem está no poder, a que este reino serve de mediador. E, portanto, condena tudo que poderia colocar sob julgamento sua opção. [...] exclui os contatos que poderiam trazer à luz algo de seu caráter suspeito" (ADORNO, 1996, p. 22-23). A linguagem do conhecimento é alterada para aquela que mais se aproxima aos interesses do capital privado, prejudicando a fomentação da crítica e do pensamento heterodoxo nas metodologias pedagógicas, substituindo-as pelo simples racionalismo positivista - entusiasta aos burgueses - ao sacralizar a industrialização e o progresso capitalista pela técnica e pela ciência. Os inúmeros programas e políticas educacionais implantadas no Brasil reforçam o paradigma

Mas quanto mais o processo da autoconservação é assegurado da divisão burguesa do trabalho, tanto mais ele força a autoalienação dos indivíduos, que se têm de se formar no corpo e na alma segundo a aparelhagem técnica. [...] O positivismo que afinal não recuou nem mesmo diante do pensamento, essa quimera tecida pelo cérebro no sentido mais liberal do termo eliminou a última instância intermediária entre a ação individual e a norma social. O processo técnico, no qual o 
sujeito se coisificou após sua eliminação da consciência, está livre da plurivocidade do pensamento mítico bem como de toda significação em geral, porque a própria razão se tornou um mero adminículo da aparelhagem econômica que a tudo engloba. (ADORNO e HORKHEIMER, 1985, p. 36-37).

\section{Considerações finais}

Na construção do processo contínuo de formação esclarecedora, o autoconhecimento é essencial para uma ação dialética. Ao se propor uma práxis que substitui a prática, Ghedin (2005) deseja que a inserção da reflexão filosófica nas metodologias pedagógicas interrompa que toda ideologia continue sua diligência deturpadora da realidade e vinculada à dissimulação de interesses. Além disso, torna-se necessário empregar o exercício de estranhamento dos padrões e valores estabelecidos que devam deixar de serem vistos com dados naturais e relativizados sob a concepção de se tratam de composições histórico-sociais, pois "ao mesmo tempo em que se iludem, os indivíduos inquietos podem questionar suas próprias ilusões" (KONDER, 2002, p. 259).

A tarefa de educar deve basear-se em valores éticos humanistas e no seu viés antropocêntrico, não ao considerar o homem como centro do universo, mas ao ampliar a medida de seu papel no julgamento de seus próprios valores e percepções que ganham significação apenas se relacionadas à sua existência (FROMM, 1970).

Se um sistema educacional propicia a autorreflexão e uma visão crítica nos parâmetros políticos voltados para a área, é possível galgar um novo rumo social desvinculado às ideologias exploratórias do trabalho e da mente humana. "Se a essencialidade do processo educativo situa-se na reflexão, como horizonte da autocompreensão, a possibilidade da cidadania ocorre na mesma proporção em que tal processo possa ser instaurado, através do ensino" (GHEDIN, 2005, p. 146).

Assim como o cunho libertador e de emancipação inerente a toda práxis, a aplicação da reflexão crítica não deve ser imposta e nem ser tratada como obrigação, todavia é necessário que seja estimulada em todos os níveis e fases educacionais (GHEDIN, 2005), a começar pela revalorização do papel do docente não somente sala de aula, mas em todo o processo formativo, desafiando por meio da reflexão e da crítica seu espaço essencial na relação dialética do sujeito com o mundo, no caso, do fazer ao saber e do saber ao refazer (VALADARES, 2005).

Não basta apenas limitar a aplicação dessa práxis em determinados ciclos ou restringir esse processo a casos isolados, que progressivamente se tornarão exceções, reduzindo-a ao patamar utópico. Mesmo que se trate de um caminho árduo e tortuoso, com lentos sinais de concretização, 
torna-se indispensável empregar esforços para uma total revolução na maneira de pensar os cenários político-sociais do Brasil no futuro e na atualidade, considerando que a chave para o verdadeiro e prodigioso progresso está encadeada a uma Educação libertária que abra à possibilidade de romper com as cadeias econômicas e políticas que violentam e exploram a força e a vontade humana. Sendo estabelecido um sistema de valores humanos que reintere uma consciência íntegra e cidadã capaz de pensar e refletir sondando a alteridade (GADOTTI, 2000).

Criar e criticar não somente os fatores que a contradizem, mas também e principalmente a si mesma, a fim de não emergir-se em uma vã ideologia que coíba assim como as outras a percepção dos acontecimentos, dissimulando-os.

\section{Referências}

ADORNO, T. W. Teoria da Semicultura. Tradução RAMOS-DEOLIVEIRA, N. et al. Educação e Sociedade, ano XVII, n. 56, p. 388-411, dez. 1996.

ADORNO, T. W.; HORKHEIMER, M. Dialética do Esclarecimento: fragmentos filosóficos. Tradução de Guido Antonio de Almeida. Rio de Janeiro: Jorge Zahar Ed., 1985.

CAMOZZATTO, V. C. Da pedagogia às pedagogias - formas, ênfases e transformações. 2012. 203 f. Tese (Doutorado em Educação) - Faculdade de Educação, Universidade Federal do Rio Grande do Sul, Porto Alegre, 2012.

CASTRO, M. H. M.. Estado e Mercado na regulação do ensino superior. In: BROCK, C; SCHWARTZMAN, S. (Orgs.). Os desafios da educação no Brasil. Rio de Janeiro: Nova Fronteira, 2005, p. 235-274.

COMTE, A. Discurso sobre o espírito positivista (1844). Tradução de José Arthur Gianotti e Miguel Lemos. In: Os pensadores. São Paulo: Abril Cultural, 1978, p. 114-227.

CONTRERAS, Domingo José. La autonomía del profesorado. Madrid: Morata, 1997.

CRUZ, A. G. A educação superior brasileira ruma à universidade oligopolista. Diálogos, Canoas, n. 30, p. 55-72, dez. 2015. Disponível em <http://revistas.unilasalle.edu.br/index.php/Dialogo/article/view/2312 $>$. Acesso em 01 de jun. 2016. 
EAGLETON, T. Ideologia: uma introdução. Tradução de Silvana Vieira e Luís Carlos Borges. São Paulo: Editora da Universidade Estadual Paulista: Editora Boitempo, 1997.

FREITAG, M. Le naufrage de l'université. Paris, Editions de la Découverte, 1996.

FROMM, E. Análise do homem. Tradução de Octávio Alves Velho. Rio de Janeiro: Jorge Zahar Ed., 1970.

GADOTTI, M. Perspectivas atuais da Educação. São Paulo em Perspectiva, São Paulo, v. 14, n. 2, p. 03-11, 2000. Disponível em: < http:/ / www.scielo.br/scielo.php?pid=S0102$88392000000200002 \&$ script=sci_abstract>. Acesso em 07 de jun. 2016.

GHEDIN, E. Professor reflexivo: da alienação da técnica à autonomia da crítica. In: PIMENTA, S. G.; GHEDIN, E. (Orgs.). Professor reflexivo no Brasil: gênese e crítica de um conceito. 3. ed. São Paulo: Cortez, 2005, p. 129-150.

GIROUX, H. Los profesores como intelectuales. Hacia una pedagogía crítica del aprendizaje. Barcelona/Madrid: Paidós/MEC, 1990.

GOYA, W. Liberdade e psicanálise na filosofia social de Erich Fromm.

Fragmentos de cultura, Goiânia, v. 18, n. 9/10, p. 811-830, set./out. 2008.

Disponível em < http://seer.ucg.br/index.php/fragmentos/article/view/726>. Acesso em 04 de jun. 2016.

HESSEN, J. Teoria do Conhecimento. Tradução de João Vergílio Gallerani Cuter. $2^{\text {a }}$ Ed. São Paulo: Martins Fontes, 2003.

KONDER, Leandro. A questão da ideologia. São Paulo: Cia das Letras, 2002.

PIMENTA, S. G. Professor reflexivo: construindo uma crítica. In: PIMENTA, S. G.;GHEDIN, E. (Orgs.). Professor reflexivo no Brasil: gênese e crítica de um conceito. 3. ed. São Paulo: Cortez, 2005, p. 17-52.

PUCCI, B. A Escola e a Semiformação mediada pelas novas tecnologias. In: PUCCI, B. (Org.); LASTÓRIA, Luiz Antonio Calmon Nabuco (Org.). Experiência formativa E emancipação. 1 ed. São Paulo: Nankin, 2009.

SCHWARTZMAN, S. Os desafios da educação no Brasil. In: BROCK, C.; SCHWARTZMAN, S. (Orgs.). Os desafios da educação no Brasil. Rio de Janeiro: Nova Fronteira, 2005, p. 9-50. 
VALADARES, J. M. O professor diante do espelho: reflexões sobre o conceito de professeor reflexivo. In: PIMENTA, S. G.; GHEDIN, E. (Orgs.). Professor reflexivo no Brasil: gênese e crítica de um conceito. 3. Ed. São Paulo: Cortez, 2005, p. 187-200.

WILLIAMS, R. Cultura. Tradução de Lólio Lourenço de Oliveira. Rio de Janeiro: Paz e Terra, 1992.

WILLIAMS, R. Marxism and Literature. Oxford: Oxford University Press, 1977.

Submetido em: 11/01/2017

Aprovado em: 01/03/2017 